\title{
Mola hidatiforme: um relato de caso
}

\author{
Hydatidiform mole: a case report
}

Mola hidatiforme: reporte de un caso

Camila Pereira Miranda Costa1, Giovanna Stefanne Lópes Barbosa1*, Ariane Oliveira Dinato", Caroline Camargo Bandeira da Silveira Luz¹, Sabrina Vergani Araújo Teixeira Costa1.

\section{RESUMO}

Objetivo: Relatar um caso típico de mola hidatiforme, seu diagnóstico, conduta e seguimento. Detalhamento do caso: Paciente de 21 anos, gestante (9 semanas e 4 dias), com queixa de dor em baixo ventre e sangramento transvaginal. Em ultrassonografia transvaginal requisitada apresentava cavidade endometrial com material hiperecóico, heterogêneo e amorfo com múltiplas áreas anecogênicas sem fluxo ao doppler. Achados sugestivos de mola hidatiforme. Foi instituída internação com solicitação de curetagem uterina e realização de testes rápidos para Vírus da Imunodeficiência Humana (HIV) e sífilis (ambos não-reagentes). Hemograma, ultrassonografia abdominal e radiografia de tórax solicitadas não constavam achados de importância clínica para o caso. Após curetagem uterina e alta hospitalar, a paciente foi encaminhada para acompanhamento pós-molar ambulatorial, onde foi prescrito método anticoncepcional e dosagem sérica semanal de b-hCG, o qual negativou (resultado menor que $5 \mathrm{mUl} / \mathrm{ml}$ ) na quinta semana após a intervenção cirúrgica. Considerações finais: Profissionais da área da saúde devem estar atentos a sinais e sintomas sugestivos de doença trofoblástica gestacional, uma afecção com relativa incidência. Neste contexto, um diagnóstico e conduta precoce e eficaz são de extrema relevância, uma vez que podem evitar as complicações da continuação de uma gestação molar.

Palavras-chave: Mola hidatiforme, Complicações na gravidez, Curetagem.

\begin{abstract}
Objective: To report a typical case of hydatidiform mole, its diagnosis, management and follow-up. Case details: A 21-year-old pregnant woman ( 9 weeks and 4 days), complaining of pain in her lower abdomen and transvaginal bleeding. In requested transvaginal ultrasound, she presented an endometrial cavity with hyperechoic, heterogeneous and amorphous material with multiple anechoic areas without doppler flow. Findings suggestive of hydatidiform mole. Hospitalization was instituted with a request for uterine curettage and rapid tests for Human Immunodeficiency Virus (HIV) and syphilis (both non-reactive). Complete blood count, abdominal ultrasound and chest radiography did not contain findings of clinical importance for the case. After uterine curettage and hospital discharge, the patient was referred for outpatient post-molar follow-up, where a contraceptive method and weekly serum b-hCG were prescribed, which was negative (result less than $5 \mathrm{mUl} / \mathrm{ml}$ ) in the fifth week after the intervention. surgical. Final considerations: Health professionals should be aware of signs and symptoms suggestive of gestational trophoblastic disease, a condition with a relative incidence. In this context, an early and effective diagnosis and conduct are extremely important, since they can avoid the complications of the continuation of a molar pregnancy.
\end{abstract}

Keywords: Hydatidiform mole, Pregnancy complications, Curettage.

${ }^{1}$ Universidade Federal do Delta do Parnaíba (UFDPar), Parnaíba - PI. *E-mail: gistefanne@gmail.com

Financiado pela Fundação de Amparo à Pesquisa do Piauí (FAPEPI) - Bolsa no 3000349

SUBMETIDO EM: 3/2021

ACEITO EM: 4/2021

PUBLICADO EM: 5/2021 


\section{RESUMEN}

Objetivo: Informar un caso típico de mola hidatiforme, su diagnóstico, manejo y seguimiento. Detalles del caso: una mujer embarazada de 21 años (9 semanas y 4 días), que se queja de dolor en la parte inferior del abdomen y sangrado transvaginal. En la ecografía transvaginal solicitada presentó una cavidad endometrial con material hiperecogénico, heterogéneo y amorfo con múltiples áreas anecogénicas sin flujo doppler. Hallazgos sugestivos de mola hidatiforme. La hospitalización se inició con una solicitud de legrado uterino y pruebas rápidas para el virus de la inmunodeficiencia humana $(\mathrm{VIH})$ y la sífilis (ambos no reactivos). El hemograma completo, la ecografía abdominal y la radiografía de tórax no arrojaron hallazgos de importancia clínica para el caso. Tras el legrado uterino y el alta hospitalaria, la paciente fue remitida para seguimiento posmolar ambulatorio, donde se prescribió método anticonceptivo y b-hCG sérica semanal, que resultó negativo (resultado inferior a $5 \mathrm{mUl} / \mathrm{ml}$ ) en la quinta semana posterior. la intervención quirúrgica. Consideraciones finales: Los profesionales de la salud deben conocer los signos y síntomas que sugieran enfermedad trofoblástica gestacional, una condición con una incidencia relativa. En este contexto, un diagnóstico y una conducta tempranos y efectivos son de suma importancia, ya que pueden evitar las complicaciones de la continuación de un embarazo molar.

Palabras clave: Mola hidatiforme, Complicaciones del embarazo, Legrado.

\section{INTRODUÇÃO}

Doença Trofoblástica Gestacional (DTG) consiste num grupo heterogêneo de lesões decorrentes da proliferação anormal do trofoblasto, cito e sinciciotrofoblasto. Possuem capacidade de malignização, apresentando-se na forma de Neoplasia Trofoblástica Gestacional (NTG) (MATTOS ACGBF, et al., 2020). No Brasil, estima-se 1 caso de doença trofoblástica gestacional em cada 200-400 gestações (LOPEZ CL, et al., 2018). Essa prevalência varia nas diferentes regiões do mundo, assim como varia de acordo com os tipos de gravidez molar. Além disso, fatores de risco como extremos de idade (maior de 35 anos ou menor de 20 anos) e história prévia de DTG mostram predileção à doença (ZUGAIB M, 2016; BRAGA A, et al., 2018; HAHN L, et al., 2018).

A suspeita de gravidez molar ocorre quando há sangramento vaginal, manifestação mais comum da doença. Outras manifestações clínicas incluem útero maior que o esperado para idade gestacional, cisto ovarianos tecaluteínicos, hiperêmese, sinais de hipertireoidismo (taquicardia, exoftalmia, extremidades quentes, pele úmida, tremores), presença de doença hipertensiva específica da gestação antes de 20 semanas e hCG com valores aumentados excessivamente (ZUGAIB M, 2016; ALMEIDA LOG, et al., 2019; CAVALCANTE MVEB, et al., 2021). Pode cursar com dor abdominal e eliminação vaginal de vesículas (patognomônico), no entanto, devido a disponibilidade de exames de imagem como a ultrassonografia e dosagem de beta-hCG, o diagnóstico e tratamento costumam acontecer antes de manifestações tardias da doença (ZUGAIB M, 2016; BRAGA A, et al., 2018; HAHN L, et al., 2018).

A ultrassonografia, somada à dosagem de beta-hCG sanguíneo, são os métodos preferenciais no diagnóstico de DTG (RAMOS BV, et al., 2021). A análise histológica do material placentário possibilita a diferenciação entre os diferentes tipos de mola, no entanto, não é mandatória para estabelecer um tratamento adequado. Pacientes com quadro clínico sugestivo de gestação molar devem realizar rastreio para metástase trofoblástica e devem ser encaminhadas para esvaziamento uterino, o qual só poderá acontecer após controle de possíveis quadros secundários, como anemia, doença hipertensiva específica da gestação e hipertireoidismo. Faz-se necessário o acompanhamento pós-esvaziamento, uma vez que o quadro pode evoluir para NTG. A dosagem sérica de beta-hCG possibilita o acompanhamento pós-molar, apontando para possível evolução da doença em caso de valores persistentes ou elevados (ZUGAIB M, 2016; BRAGA A, et al., 2018).

O objetivo do presente relato foi retratar um caso típico de paciente jovem com sangramento vaginal e o seguimento realizado para investigação, diagnóstico, tratamento e acompanhamento pós-molar num Centro Integrado de Especialidades Médicas (CIEM) em um município no litoral do Piauí. 


\section{DETALHAMENTO DO CASO}

O seguinte relato foi autorizado pela paciente mediante termo de consentimento livre esclarecido, disponível em caso de necessidade de comprovação ética. Paciente, sexo feminino, 21 anos, procedente da zona rural do município de Madeiro no Piauí, procurou atendimento médico no setor de obstetrícia de um hospital, na cidade de Parnaíba, Piauí, dia 19 de janeiro de 2021. Relatou sangramento transvaginal e dor em baixo ventre (3 em escala de 1 a 10), além de negar perda de líquido. Negou também sintomas relacionados à infecção pelo SARS-CoV-2. Como antecedentes obstétricos, observou-se gestação atual com idade gestacional de 9 semanas e 4 dias, nenhuma gestação anterior, parto ou aborto (G1P0A0).

Ao exame físico, pressão arterial ligeiramente aumentada: 130x90 mmHg, frequência cardíaca de 106 batimentos por minuto e temperatura axilar de $36,5^{\circ} \mathrm{C}$. Foram solicitados os seguintes exames complementares: Ultrassonografia Transvaginal (USG-TV), tipagem sanguínea de acordo com o sistema ABO e fator Rh e hemograma completo.

Laudo USG-TV (19/01/2021): Cavidade endometrial com material hiperecoíco, heterogêneo e amorfo com múltiplas áreas anecogênicas sem fluxo ao doppler. Achados sugestivos de mola hidatiforme. $O$ exame de tipagem sanguínea resultou grupo $\mathrm{O}$, fator Rh positivo. Não foram observadas alterações no hemograma completo.

Conduta: internação com solicitação de curetagem uterina e realização de testes rápidos para Vírus da Imunodeficiência Humana (HIV) e sífilis - ambos não-reagentes. À internação, foi prescrito dieta zero, administração de quatro comprimidos de misoprostol de $200 \mathrm{mcg}$, via vaginal, e $500 \mathrm{ml}$ de soro glicosado $5 \%$ intravenoso. Solicitou-se, ainda, Ultrassonografia de Abdome Total (USG-AT) e radiografia de tórax em incidência AP (anteroposterior) e perfil RX tórax.

Laudo RX tórax (19/01/2021): Opacidades nodulares com diâmetro médio de 1,0 $\mathrm{cm}$ projetadas no lobo superior direito. Laudo TC tórax (21/01/2021): Opacidades lineares esparsas, predominando na base esquerda de aspecto residual/cicatricial. Pequenos nódulos calcificados no lobo inferior esquerdo, com aspecto residual. Ausência de derrame pleural. Ausência de linfonodomegalias. Área cardíaca preservada. Tais achados sem importância clínica para o quadro obstétrico da paciente.

No segundo dia de internação, a paciente foi encaminhada ao centro cirúrgico, onde foi realizada a curetagem uterina a qual consistiu em: 1. Paciente sob sedação em posição ginecológica; 2. Assepsia e antissepsia 3. Curetagem de restos ovulares e vesículas; 4. Esvaziamento endometrial. Após o procedimento cirúrgico, a paciente retornou ao leito, onde foi verificada formação de globo de segurança de Pinard e eliminação de lóquios fisiológicos. Posteriormente, foi prescrito dieta livre, soro fisiológico $0,9 \% \mathrm{NaCl}$ via intravenosa e dipirona se necessário.

No primeiro dia pós-operatório a paciente encontrava-se sem queixas. Ao exame físico, bom estado geral, lúcida e orientada no tempo e espaço, acianótica, anictérica, afebril, eupneica e hipocorada (+/4+). A conduta se manteve, havendo adição de 1 comprimido ao dia de sulfato ferroso via oral e solicitação de beta-HCG quantitativo, o qual resultou em $146.447,1 \mathrm{mIU} / \mathrm{ml}$. No segundo dia pós-operatório a paciente recebeu alta hospitalar, sendo encaminhada para acompanhamento ambulatorial em clínica médica da cidade.

Foi indicado Método Anticoncepcional Injetável trimestral. Ao sexto dia pós-operatório, a paciente realizou nova USG-TV sem anormalidades. Ao sétimo dia pós-operatório, dosagem de beta-HCG apresentou uma redução para $3.257,09 \mathrm{mUI} / \mathrm{ml}$. Demais resultados seriados da dosagem de beta-HCG seguem: 461,29 $\mathrm{mUI} / \mathrm{mL}$ (05/02/2021), 81,1 mUl/mL(12/02/2021), 23,85 mUl/mL (19/02/2021), negativando, ou seja, com resultado menor que $5 \mathrm{mUl} / \mathrm{ml}, 37$ dias após a realização da curetagem (26/02/2021).

\section{DISCUSSÃO}

A Doença Trofoblástica Gestacional consiste num grupo heterogêneo de lesões decorrentes da proliferação anormal do trofoblasto, cito e sinciciotrofoblasto, abrangendo o coriocarcinoma, o tumor trofoblástico do sítio placentário, a mola invasiva e as diversas formas da mola hidatiforme, estas benignas e mais comuns dentre todos os tipos de DTG (CORRÊA IB, et al., 2018). 
Apesar de benigna, a Mola Hidatiforme (MH) tem potencial de evolução para doença com comportamento maligno, sendo, por isso, importante seu diagnóstico e tratamento precoce. A MH compreende duas entidades distintas entre si, a Mola Hidatiforme Parcial (MHP) e a Mola Hidatiforme Completa (MHC). A MHP acontece em casos de triploidia, a qual resulta de erro de fertilização por mecanismos diversos como dispermia, fertilização de um óvulo haplóide por um espermatozóide diplóide, fertilização de um óvulo diplóide por um espermatozoide haploide ou quando um óvulo normal é fecundado por dois espermatozoides. Nesta entidade, o feto, cordão e membrana amniótica estão frequentemente presentes. Os vilos edematosos (vilosidades hidrópicas) apresentam hiperplasia moderada, sem anaplasia celular. Na ultrassonografia a placenta se apresenta extensamente aumentada, com espaços císticos em seu interior e cavidade amniótica que tanto pode estar vazia como pode conter ecos fetais ou concepto vivo com crescimento restrito (ANDRADE MJ, 2009; CORRÊA IB, et al., 2018).

Já na MHC, que é a condição mais frequente do grupo das DTGs, acontece um erro de fertilização em que um óvulo perde sua carga genética haplóide (têm-se um óvulo sem núcleo ativo), sendo fecundado por espermatozóide aparentemente normal. Assim, todos os genes são de origem paterna. A seguir, ocorre a duplicação dos cromossomos paternos, porém com ausência da divisão celular concomitante, o que viabiliza um zigoto com número habitual de cromossomos. Neste caso, feto, cordão e membrana são sempre inexistentes, o trofoblasto demonstra intensa hiperplasia com anaplasia celular (SHAABAN AM, et al., 2017). A ultrassonografia é caracterizada por útero de grande volume para a idade gestacional que apresenta, internamente, abundantes ecos amorfos, aos quais se mesclam formações arredondadas e anecóicas de diversos tamanhos indicadoras de vesículas, configurando uma imagem em "flocos de neve" (CORRÊA IB, et al., 2018).

Clinicamente, o volume uterino aumentado e complicações como hiperêmese, pré-eclâmpsia e eliminação de vesículas são mais frequentes nas portadoras de MHC. No entanto, com a evolução tecnológica da ultrassonografia e sua popularização, houve o aumento na suspeição diagnóstica da mola hidatiforme mais precocemente, não permitindo a doença evoluir com tais complicações e com imagens mais sugestivas, contribuindo assim para uma maior dificuldade em diferenciar tais entidades. Já a clínica das pacientes com MHP geralmente é caracterizada por sintomas semelhantes ao abortamento incompleto ou retido: sangramento, dor pélvica e um volume uterino menor para a idade gestacional em comparação ao volume uterino da MHC. Em suma, a diferenciação dessas duas entidades de mola hidatiforme tem sido feita quase sempre por meio da avaliação histológica de material curetado. Uma vez que tal análise histológica não é mandatória no seguimento da doença, muitas vezes não é feita, como no caso aqui relatado. Entretanto, tal análise é interessante, por exemplo, para estudos de incidência e epidemiologia (CORRÊA IB, et al., 2018; FEBRASGO, 2018).

O diagnóstico precoce tem mudado a epidemiologia e a forma de apresentação da $\mathrm{MH}$. Tem sido relatado uma diminuição na média de idade das pacientes, além de volumes uterinos menores. O sangramento vaginal continua como sintoma mais relevante, apresentando-se na maioria dos casos entre a quarta e a décima sexta semana de amenorreia (CORRÊA IB, et al., 2018; FEBRASGO, 2018). Tais aspectos corroboram com o caso aqui relatado, uma vez que se trata de uma paciente de 21 anos (fora da incidência mais comum) a qual tem como queixa principal sangramento transvaginal presente na nona semana de gestação.

A apresentação das DTGs é caracterizada pela detecção sérica exorbitante de um marcador tumoral biológico e específico, a Gonadotrofina Coriônica Humana ( $\mathrm{hCG}$ ), um hormônio produzido pelo sinciciotrofoblasto placentário. Os níveis séricos de hCG nas portadoras de MHC são intensamente elevados, cerca de $50 \%$ das pacientes têm níveis superiores a $100.000 \mathrm{mUl} / \mathrm{mL}$. Esses níveis, entretanto, são muito inferiores nos casos de MHP, valores maiores que $100.000 \mathrm{mUl} / \mathrm{mL}$ são observados somente em $10 \%$ dos casos. No caso relatado a paciente apresenta um hCG de $146.447,1 \mathrm{mUl} / \mathrm{ml}$ e uma imagem da cavidade endometrial com material hiperecóico, heterogêneo e amorfo com múltiplas áreas anecogênicas além de ausência de feto, tendendo mais para um diagnóstico de mola hidatiforme completa (SOUSA EM, et al., 2019).

No que tange ao tratamento, uma vez suspeitado de gravidez molar, a paciente precisa ser avaliada a fim de detectar complicações, dentre elas anemia, hemorragia, cistos tecaluteínicos, síndrome de 
hiperestimulação ovariana, pré-eclâmpsia, hipertireoidismo, síndrome de angústia respiratória aguda, embolização trofoblástica, edema agudo de pulmão e tromboembolismo pulmonar, mediante realização de exames complementares como hemograma completo, exames bioquímicos, função hepática e tireoidiana, urinálise e radiografia de tórax. Além disso, é interessante que a avaliação pré-operatória inclua, também, tipagem sanguínea, dosagem sérica de hCG e eletrocardiograma, este se houver necessidade. Tal avaliação pré cirúrgica da paciente relatada foi realizada, com resultados sem alterações, permitindo, seguidamente, a intervenção cirúrgica (FERRAZ L, et al., 2015).

O tratamento da $\mathrm{MH}$ compreende duas fases, sendo elas o esvaziamento do útero e o seguimento pósmolar. No esvaziamento uterino, a indução do abortamento molar e histerotomia são métodos não recomendados, uma vez que aumentam a morbimortalidade materna por propiciar grande perda sanguínea e um esvaziamento incompleto, o que impõe curetagem. Além disso, podem aumentar, ainda, a possibilidade de embolização trofoblástica e ampliar o risco de disseminação trofoblástica, bem como propiciar o desenvolvimento de neoplasia trofoblástica gestacional.

Apesar de alguns locais realizarem, ainda, a curetagem uterina como método de esvaziamento molar, este tem sido atualmente substituído devido seu maior risco de perfuração uterina, uma vez que deixa a parede do útero mais fina e flexível, além de ampliar o risco de sinéquias (MORAES VP, et al., 2014; FERRAZ L, et al., 2015).

A aspiração uterina tem sido o método de escolha, sendo a aspiração manual intrauterina (AMIU) a ferramenta mais difundida no Brasil, podendo ser utilizada independente do tamanho do útero (LIMA LLA, et al., 2017). Tanto no método da curetagem quanto na aspiração é imprescindível a infusão venosa de ocitocina com o intuito de reduzir o risco de desenvolvimento de edema agudo de pulmão, bem como de hipotensão. Em casos de útero muito volumosos com alto risco de perfuração ou hemorragia intraoperatória, macrodoses de ocitocina podem ser utilizadas, no máximo 40 UI (SIQUEIRA WC, et al., 2010; FERRAZ L, et al., 2015; FEBRASGO, 2018).

Por fim, no seguimento pós-molar a maioria das pacientes cursam com diminuição progressiva de betahCG e nenhum tratamento adicional se faz necessário. No entanto, este seguimento deve ser pontual e rigoroso e é realizado por meio da dosagem semanal ou quinzenal de beta-hCG plasmático até sua normalização (MAESTÁ I e BRAGA A, 2012; FERRAZ L, et al., 2018).

No caso relatado, a paciente, após alta hospitalar, foi encaminhada para o acompanhamento ambulatorial obstétrico onde foram dosados seus níveis de beta-hCG, o qual normalizou na quinta semana pós-operatório, excluindo doença residual ou persistente. É importante, ainda, propor à paciente um método de contracepção imediatamente após o esvaziamento uterino que deve permanecer durante o tempo de seguimento (LIMA LLA, et al., 2016). O uso de anticoncepcional hormonal oral é a escolha mais comum das pacientes. É seguro e não aumenta o risco de NTG. Na paciente relatada a escolha foi o método anticoncepcional injetável, também seguro e eficaz (SOCEGO, 2017; FEBRASGO, 2018).

Conclui-se que a Doença Trofoblástica Gestacional requer profissionais atentos aos sinais e sintomas sugestivos da patologia, sendo sangramento vaginal o mais comumente referido pelas pacientes. Outros sintomas como útero maior que o esperado para a idade gestacional, hiperêmese, hipertireoidismo, doença hipertensiva gestacional com menos de 20 semanas e cistos ovarianos tecaluteínicos também são factíveis. Apesar de possuir bom prognóstico, é uma afecção de relativa incidência e potencial de malignização, principalmente em casos de diagnóstico tardio. Por isso, um diagnóstico e conduta precoce são de extrema relevância, uma vez que podem evitar as complicações da gestação molar. Este relato contribui na caracterização do quadro clínico comumente encontrado, permitindo que o profissional de saúde reconheça e estabeleça de forma eficaz a conduta correta para o caso.

\section{FINANCIAMENTO}

Financiado pela Fundação de Amparo à Pesquisa do Piauí (FAPEPI); modalidade bolsa. 


\section{REFERÊNCIAS}

1. ALMEIDA LOG, et al. Mola hidatiforme parcial e completa: características clínicas e histológicas. Rev Med UFC, 2019; 59(4): 46-50.

2. ANDRADE MJ. Mola hidatiforme e doença trofoblástica gestacional. Revista Brasileira de Ginecologia e Obstetrícia, 2009; 31(2): 94-101.

3. BRAGA A, et al. Doença trofoblástica gestacional. Protocolo Febrasgo - Obstetrícia, no 23/Comissão Nacional Especializada em Doença Trofoblástica Gestacional, 2018.

4. CAVALCANTE MVEB, et al. Enfermidades maternas associadas à mola hidatiforme: uma revisão sistemática. Rev Ciên Saúde, 2021; 6(1): 1-5.

5. CORREAA IB, et al. Comorbidades Associadas à Mola Hidatiforme: Como Diagnosticar e Tratar. Revista de Patologia do Tocantins, 2018; 5(3): 68-74.

6. FEBRASGO. Protocolo Febrasgo - Obstetrícia, № 23/Comissão Nacional Especializada em Doença Trofoblástica Gestacional. 2018.

7. FERRAZ L, et al. Atualização no diagnóstico e tratamento da gravidez molar. Jornal Brasileiro de Medicina, 2015; 103(2): 6-12.

8. FERRAZ L, et al. Doença Trofoblástica Gestacional: como diagnosticar e tratar? Saber Científico, 2018; 7(1): 83-90.

9. HAHN L, et al. Doença trofoblástica gestacional: diagnóstico e tratamento. Acta méd, 2018; 136-150.

10. LIMA LLA, et al. Correlações clinicorradiológicas em pacientes com doença trofoblástica gestacional. Radiol Bras, 2016; 49(4): 241-250.

11. LIMA LLA, et al. Papel da cirurgia no manejo de mulheres com doença trofoblástica gestacional. Rev. Col. Bras. Cir., 2017; 44(1): 94-101.

12. LOPEZ CL, et al. Gestational Trophoblastic Neoplasia after Ectopic Molar Pregnancy: Clinical, Diagnostic, and Therapeutic Aspects. Rev. Bras. Ginecol. Obstet., 2018; 40(5): 294-299.

13. MAESTÁ I, BRAGA A. Desafios do tratamento de pacientes com doença trofoblástica gestacional. Rev. Bras. Ginecol. Obstet., 2012; 34(4): 143-146.

14. MATTOS ACGBF, et al. Diagnóstico, tratamento e seguimento da mola hidatiforme: uma revisão bibliográfica. Revista Eletrônica Acervo Científico, 2020; 13 (e5184):1-6.

15. MORAES VP, et al. Complicações clínicas da gravidez molar. FEMINA, 2014; 42(5): 229-234.

16. RAMOS BV, et al. Mola hidatiforme: manifestações clínicas e critérios diagnósticos por imagem. Brazilian Journal of Health Review, 2021; 4(1): 3607-3616.

17. SHAABAN AM, et al. Gestational Trophoblastic Disease: Clinical and Imaging Features. RadioGraphics, 2017; 37: 681-700.

18. SIQUEIRA WC, et al. Doença trofoblástica gestacional: lições de um caso paradigmático. Rev Med Minas Gerais, 2010; 20(2 supl 1): S110-S113.

19. SOCEGO. Nascer no Ceará: Condutas Assistenciais para a Linha de Cuidado Materno-infantil do Estado do Ceará. 2017.

20. SOUSA EM, et al. Variabilidade interobservador no diagnóstico da doença trofoblástica gestacional: um estudo na residência de patologia da Universidade Federal do Ceará. Rev Med UFC, 2019; 59(4):22-26.

21. ZUGAIB M. Obstetrícia. Barueri: Manole, 2016;1315p. 